\title{
Originals
}

\section{Effect of feeding, fasting, and diabetes on liver glycogen synthase activity, protein, and $\mathrm{mRNA}$ in rats}

\author{
M.C. G annon ${ }^{1,2,3}, \mathbf{F Q}$. N uttall ${ }^{1,3}$ \\ ${ }^{1}$ Metabolic Research Laboratory, V. A. Medical Center, Minneapolis, Minnesota, USA \\ ${ }^{2}$ Departments of Food Science and Nutrition, Minneapolis, Minnesota, USA \\ ${ }^{3}$ Department of Medicine, University of Minnesota, Minneapolis, Minnesota, USA
}

Summary Hepatic glycogen synthase activity is increased in diabetic animals. However, the relationship between enzymic activity, enzyme protein mass, and mRNA abundance has not been well characterized. In the present study, these relationships were determined in 3- and 8-day diabetic, fed and fasted rats. The results were compared to data obtained in normal fed and fasted animals. In normal rats, total synthase specific activity and protein mass were similar in the fed and fasted state. However, in fed animals, the synthase mRNA abundance was increased 1.7-fold. In 3-day diabetic rats, total synthase specific activity was increased approximately $29 \%$ compared to normal controls. It was unaffected by feeding and fasting and was associated with an approximate $15 \%$ increase in enzyme mass. Synthase mRNA was increased 1.8 and 2.6-fold in fasted and fed animals, respectively. In 8-day diabetic rats, total synthase specific activity was increased more than 2-fold compared to controls. However, the enzyme protein mass was decreased by approximately $20 \%$. The mRNA abundance in 8-day diabetic fasted rats was only $30 \%$ of controls, while in fed rats it was increased by $40 \%$. These data indicate that feeding and fasting have a major effect on synthase mRNA abundance which is independent of synthase activity, or protein mass, or both, in normal and diabetic animals. Total synthase specific activity increased with duration of diabetes. This was associated with only a modest change in protein mass. Thus, diabetes induces an increase in synthase catalytic efficacy. The specific activity of phosphorylase is decreased in diabetic rats. [Diabetologia (1997) 40: 758-763]

Keywords Glycogen synthase, diabetes mellitus, mRNA, ribonuclease protection assay, Western blotting, rats, phosphorylase, glycogen.
Our laboratory [1], as well as many others [2-8], have reported an increase in total synthase activity in liver from diabetic rats. The increase in hepatic synthase activity could be due to an increased mass of the enzyme or to the presence of a more catalytically efficient form(s) of the enzyme. Akatsuka et al. [5]

Received: 18 October 1996 and in revised form: 23 January 1997

Corresponding author: M.C. Gannon, V.A. Medical Center, One Veterans Drive, Minneapolis, MN 55417, USA

A bbreviations: mRNA, Messenger ribonucleic acid; RPA, ribonuclease protection assay; $\mathrm{M}_{\mathrm{r}}$, relative molecular weight; DTT, dithiothreitol; UTP, uridine triphosphate; ANOVA, analysis of variance. reported changes in the $\mathrm{M}_{\mathrm{r}}$ of synthase in liver from streptozotocin diabetic rats. They attributed this to an increase in the phosphorylation state of synthase, which in turn resulted in greater total synthase activity. In contrast, in alloxan diabetic rats, Bahnak and Gold [3] reported that the increase in hepatic synthase activity was due to an increased mass of the enzyme. This was associated with an increased synthesis and increased turnover rate. They could not confirm the presence of an altered form of the enzyme [9].

The purpose of the present study was to determine whether the increase in total synthase activity observed previously in diabetic rats was associated with an increase in enzyme protein mass and whether the reported increase in enzyme turnover was associated with an increase in mRNA abundance. Therefore, 
we have determined the synthase specific activity, mass of synthase protein, and mRNA abundance in liver from diabetic fed and fasted rats. The results were compared to data obtained in normal fed and fasted animals. Part of these data have been presented previously in abstract form [10].

\section{Materials and methods}

$\left[{ }^{14} \mathrm{C}\right]$-glucose and $\left[{ }^{14} \mathrm{C}\right]$-glucose-1-phosphate were obtained from du Pont NEN (Boston, Mass., USA). $\left[{ }^{14} \mathrm{C}\right]-\mathrm{UDPG}$ was prepared in our laboratory [11]. ${ }^{32} \mathrm{P}$ was purchased from Amersham Corp. (Arlington Heights, IL, USA). Sodium secobarbital (Seconal) was purchased from Eli Lilly (Indianapolis, Ind., USA). Other reagents of the highest possible purity were purchased from Sigma Chemical (St. Louis, Mo. USA). Type III rabbit liver glycogen was passed through a mixedbed ion-exchange resin before use.

Male Harlan Sprague Dawley rats (150-220 g) were housed in a temperature $\left(22^{\circ}\right)$ and light controlled (12-h cycle) animal facility. Animals were fed rat chow ad libitum. These studies were performed in adherence with the guidelines established in the Guide for the Care and Use of Laboratory Animals (NRC 1985). Animals were housed in facilities accredited by the American Association for the Accreditation of Laboratory Animal Care (AAALAC), and the research protocol was approved by the Animal Study Subcommittee of the Minneapolis VA Medical Center, and the University of Minnesota. Six groups of rats were studied: normal fed, normal $24 \mathrm{~h}$ fasted, 3day diabetic fed, 3-day diabetic $24 \mathrm{~h}$ fasted, 8-day diabetic fed, and 8-day diabetic $24 \mathrm{~h}$ fasted. Rats, fasted for 24 hours, were made diabetic by intravenous tail vein injection of alloxan $(40 \mathrm{mg} / \mathrm{kg})$. Both 3- and 8-day diabetic rats were studied in order to compare our data with those in the literature.

Animals were anaesthetized with Seconal, $50 \mathrm{mg} / \mathrm{kg}$, intraperitoneally 15 min before they were killed. Only well-anaesthetized, non-cyanotic animals were used. An abdominal incision was made. Two samples of liver were clamped in situ using liquid nitrogen cooled clamps designed in our laboratory for this purpose. One sample was wrapped in aluminum foil and stored in liquid nitrogen until assayed later the same day for synthase and phosphorylase. A second sample of frozen liver was stored at $-70^{\circ}$ for RNA extraction. Fresh, i. e. non-frozen, liver was obtained for Western blotting.

Frozen tissue was homogenized in $100 \mathrm{mmol} / \mathrm{l} \mathrm{KF}$, $10 \mathrm{mmol} / \mathrm{l}$ EDTA, pH 7.0, 1:9, w:v at $0-4^{\circ}$. The homogenate was filtered through cheese cloth. The resulting filtrate was used for assay of glycogen synthase [12], and phosphorylase [13] as previously described.

Plasma glucose was determined on a Beckman glucose analyser using an $\mathrm{O}_{2}$ electrode. Protein was determined by the colorimetric method of Zak and Cohen [14] using bovine serum albumin as standard. Glycogen was determined by the method of Carr and Neff [15] using rabbit liver glycogen as standard.

Protein mass was determined by Western blotting. The protein mass is implicitly equated with immunoreactivity as conventionally accepted. Fresh tissue was homogenized in $50 \mathrm{mmol} / \mathrm{l} \beta$-glycerophosphate, $5 \mathrm{mmol} / \mathrm{l}$ EDTA, $2 \mathrm{mmol} / \mathrm{l}$ EGTA, $100 \mathrm{mmol} / \mathrm{l} \mathrm{NaF}, 10 \mathrm{mmol} / \mathrm{l} \mathrm{DTT}, 0.5 \mathrm{mmol} / 1$ phenylmethyl sulfonyl fluoride, $0.1 \mathrm{mg} / \mathrm{ml}$ soybean trypsin inhibitor, $1 \mu \mathrm{g} / \mathrm{ml}$ leupeptin, $0.2 \mathrm{mmol} / \mathrm{l}$ tosyllysine chloromethyl ketone, $0.2 \mathrm{mmol} / \mathrm{l}$ tosylphenyl chloromethyl ketone, $\mathrm{pH} 7.0,1: 10$, w:v. Endogenous glycogen in the liver homogenate was digested with amyloglucosidase $(0.5 \%$ in citrate buffer $)$ for $24 \mathrm{~h}$ before running the gel. Samples, $15 \mu \mathrm{g}$ protein/lane, were separated on $7.5 \%$ acrylamide resolving, $4.5 \%$ acrylamide stacking gels. A single liver sample from a normal fasted rat was included in each gel as an internal control. Gels were run at 200 volts for approximately $45 \mathrm{~min}$. The proteins were electro-transferred to nitrocellulose membranes at 100 volts for $1 \mathrm{~h} 15 \mathrm{~min}$. Antibody was anti-rat liver synthase prepared in chicken (IgY). The second antibody was anti-chicken IgG (Sigma). Bio Rad avidin alkaline phosphatase conjugate (Hercules, CA, USA), para-nitroblue tetrazolium chloride, and 5-bromo-4-chloro-3indolyl phosphate were used to develop the blot.

RNA was isolated from liquid nitrogen frozen tissue which had been stored at $-70^{\circ} \mathrm{C}$ using a modification of the method of Chomczynski $[16,17]$ with TriReagent (a commercial phenol/guanidine thiocyanate combination produced by Molecular Research Center, Inc., Cincinnati, Ohio, USA). mRNA was quantified using a ribonuclease protection assay kit manufactured by Ambion (RPA II, Austin, TX, USA). RNA isolated from a single normal, fasted rat liver was included repeatedly as an internal control in each assay. The ribonuclease protection assay has been reported to be 10 times more sensitive than Northern blotting for detection of mRNA [18]. The hybridizing probe was prepared from a cDNA of rat liver glycogen synthase [19]. A 443 nucleotide transcript was synthesized with SP6 RNA polymerase and labelled with $\alpha-{ }^{32} \mathrm{P}$ UTP.

Total synthase activity referred to in the text, represents the sum of synthase $\mathrm{R}$ and synthase $\mathrm{D}$, i. e. the activity measured at a saturating concentration of the substrate, UDP-glucose, and the modifier, glucose 6-phosphate, at $\mathrm{pH} 8.5$ which represents maximal activity [12].

Statistical analysis. Statistics were determined by analysis of variance (ANOVA) with least significant difference, or by Student's t-test, as appropriate, using the Statview 512 program for the Macintosh computer. The criterion for significance was $p<0.05$.

\section{Results}

The plasma glucose concentration was significantly higher in the diabetic rats compared to the normal rats, as expected. It also was significantly higher in the fed rats compared to the fasted rats in each group (Fig. 1, top).

In the diabetic fed animals, the glycogen concentration was only approximately $50 \%$ of that in the normal fed animals and it was only slightly higher than in the diabetic fasted animals. Thus, the glycogen concentration was higher in the diabetic fasted rats compared to normals, and lower in the diabetic fed rats compared to normals.

Synthase R specific activity was significantly lower in fed rats compared to fasted rats in each group as we reported previously [12, 20-24]. The mechanism remains unknown. Total synthase specific activity was modestly greater ( $\sim 29 \%)$ in liver from 3-day diabetic rats compared to the normal animals. It was 2 times greater in liver of 8-day diabetic rats compared to normal rats (Fig. 2, top). The total synthase specific activity was unaffected by fasting or feeding in each group. 

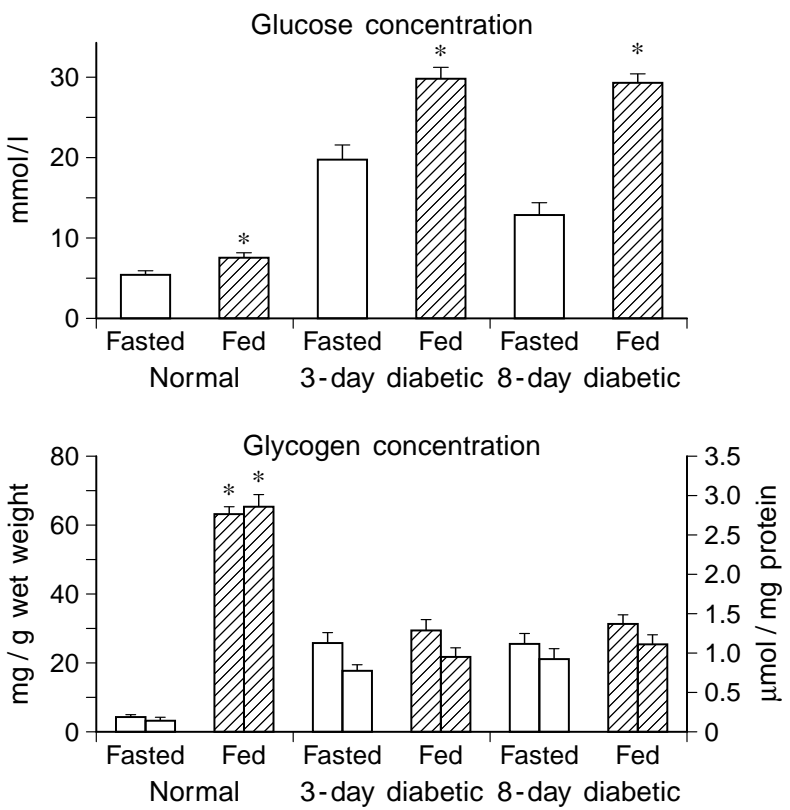

Fig. 1. Plasma glucose (top) and hepatic glycogen concentration (bottom) in normal, 3-day diabetic, or 8-day diabetic rats $(n>6)$. $\square$ Fasted rats; $\mathbb{Z}$ fed rats. In the bottom panel, the left hand bar of the pair represents data as $\mathrm{mg} / \mathrm{g}$ wet weight; the right hand bar of the pair represent data as $\mu \mathrm{mol} / \mathrm{mg}$ protein. * Statistical difference (Student's t-test) between fed and fasted animals

Phosphorylase a specific activity was significantly greater in fed animals compared to fasted rats in each group. Total phosphorylase specific activity was significantly greater in normal fed rats compared to normal fasted animals (Fig.2, bottom). The total phosphorylase specific activity was significantly lower in 3- and 8-day diabetic animals, whether fed or fasted, compared to normal fed or fasted animals. Total phosphorylase specific activity was slightly, but not statistically significantly higher, in fed compared to fasted diabetic rats. Total soluble protein was 142 in normal fasted rats; 166 in normal fed; 204 in 3-day diabetic fasted; 192 in 3-day diabetic fed; 174 in 8day diabetic fasted and $172 \mathrm{mg} / \mathrm{g}$ wet weight in 8-day diabetic fed rats.

Synthase protein mass, determined by Western blotting, was similar in liver extracts from fasted and fed rats in each individual group (Fig. 3, top). The protein mass was slightly $(\sim 15 \%)$, but significantly greater in 3-day diabetic fasted rats. It was significantly less $(\sim 20 \%)$ in 8-day diabetic fasted compared to normal fasted. It also was significantly less in 8-day diabetic fed compared to normal fed animals.

Liver synthase mRNA was greater in fed compared to fasted rats in each group. This increase was 1.7-fold in normal rats, 2.5-fold in 3-day diabetic and 7.8-fold in 8-day diabetic rats. The synthase mRNA was increased 1.8-fold in 3-day diabetic fasted rats, but was decreased 3.4-fold in 8-day diabetic-fasted rats compared to normal fasted animals. The quantity
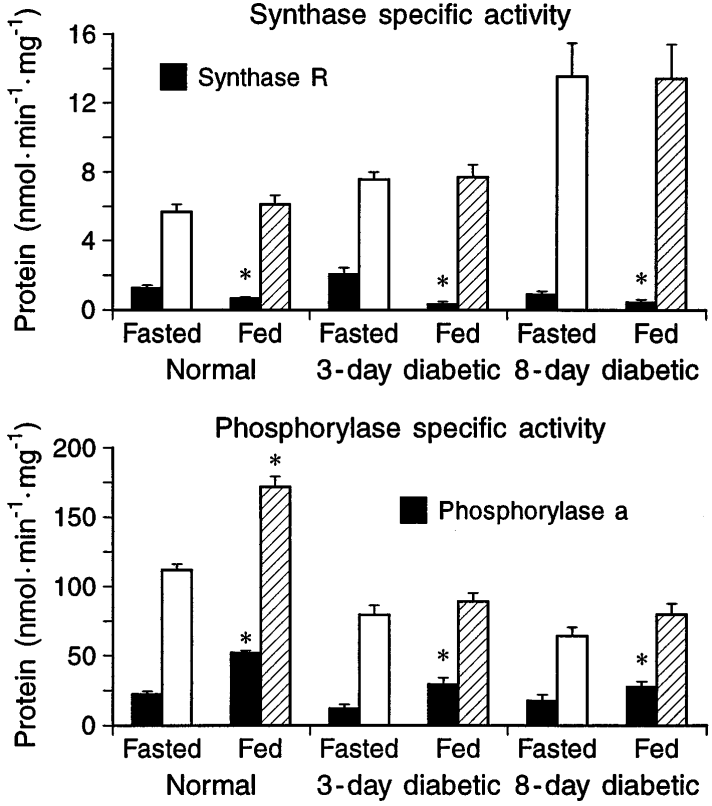

Fig. 2. Total hepatic synthase (top) and phosphorylase (bottom) specific activity in normal, 3-day diabetic, or 8-day diabetic rats $(n>6)$. $\square$ Fasted rats; $\mathbb{Z}$ fed rats, $\square$ active form(s) of the enzyme. * Statistical difference (Student's t-test) compared to the respective fasted animals

of synthase mRNA was greatest in liver from fed, 3day diabetic rats; it was least in liver from 8-day diabetic-fasted rats. Examples of Western blots and RPA blots are shown in Figure 4.

\section{Discussion}

In diabetic animals, total synthase activity has been reported to be increased by a number of laboratories [2-8], including our own [1]. Bahnak and Gold reported the activity to be greater at 8 days of diabetes than at 3 days, but the differences were not as great as noted in the present study. They also reported that the increased synthase activity was due to an increase in mass of the enzyme protein as determined by immunotitration [3]. However, Akatsuka et al. [5] reported it was due to an increase in catalytic efficiency. The latter was attributed to the synthase being phosphorylated differently in diabetic animals than in normals. In this regard, we found that liver synthase from diabetic rats was a relatively poor substrate for synthase phosphatase [25].

Bahnak and Gold [3] also reported a progressive increase in the turnover rate of synthase with time after rats were made diabetic using alloxan. In these animals the synthesis rate was increased 2.5-fold compared to normal rats, and there was little difference between 2,5 , and 8 days of diabetes. The degradation rate also was increased in the diabetic rats 

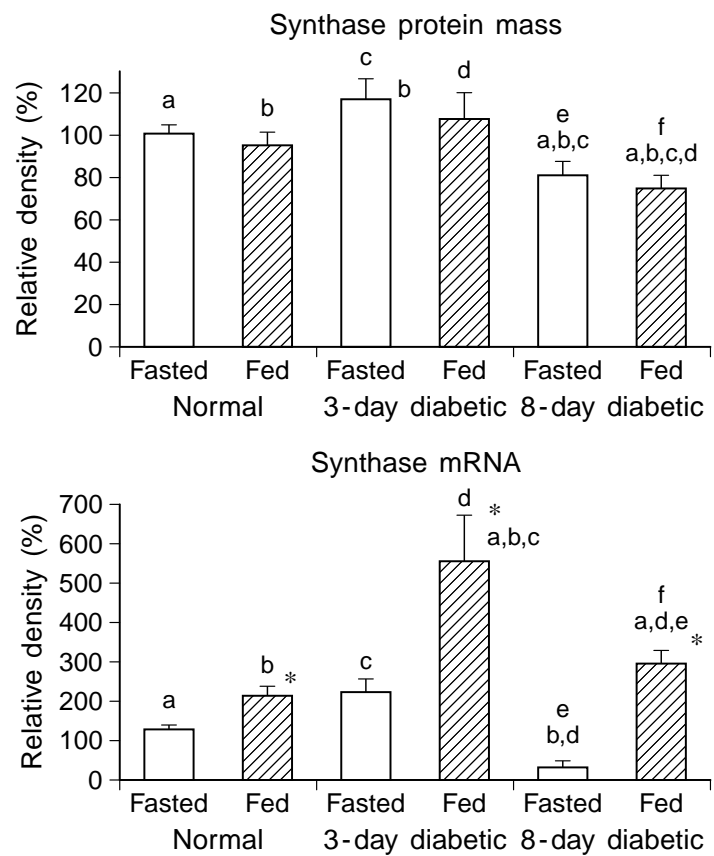

Fig. 3. Hepatic synthase protein mass (top) and synthase mRNA (bottom) in normal, 3-day diabetic, or 8-day diabetic rats $(n>6)$. $\square$ Fasted rats; $\mathbb{Z}$ fed rats. * Statistical difference (Student's t-test) compared to the respective fasted data. Bars sharing a common letter are significantly different (ANOVA). An identical amount of soluble protein was loaded onto the gel when Western blotting was performed. An internal control was included with each Western blot and ribonuclease protection assay. The density of each sample was compared to that internal control to obtain consistence between experiments

and continued to increase over the 8 day period. Their turnover data [3] can explain the small increase in synthase mass observed at 3 days and the small decrease at 8 days in the present experiments. They attributed the increase in titratable synthase to an increased synthesis rate. However, since the synthesis rate remained increased and stable, but the degradation rate continued to increase with time, a decrease in synthase mass by 8 days would be anticipated, as observed in the present studies. Although not indicated, presumably fed animals were used in their studies.

The present data indicate the synthase mRNA abundance was increased 2.6-fold in 3-day and 1.4fold in 8-day diabetic fed rats compared to data from normal fed animals. This increased mRNA abundance is compatible with the increased synthesis rate of synthase protein reported previously [3].

In fasted animals the mRNA was increased 1.8fold in 3-day diabetic animals. However, at 8 days it was decreased dramatically. To our knowledge data regarding synthase synthesis rates and turnover have not been determined in diabetic fasted animals. The decreased mRNA suggests that the protein synthesis rate is likely to be considerably diminished by 8 days.

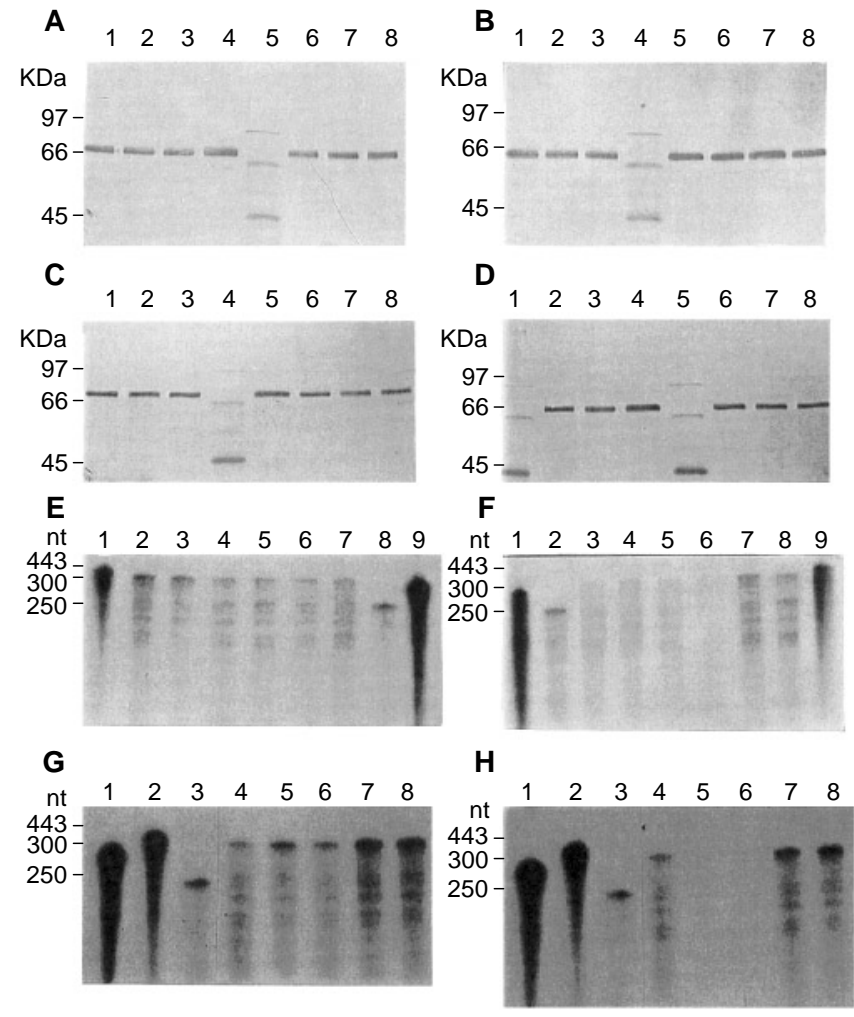

Fig. 4 A - H . Representative Western (A-D) and RPA (E-H) blots. A Lanes 1-4 Normal fasted, Lane 5 Standard, Lanes 68 3-day diabetic fasted; B Lane 1-3 3-day diabetic fed; Lane 4 Standard, Lane 5 Normal fasted, Lanes 6-8 Normal fed; C Lanes 1-3 8-day diabetic fasted, Lane 4 standard, Lane 5 Normal fasted, Lanes 6-8 8-day diabetic fed; D Lane 1 Standard, Lanes 2-3 8-day diabetic fed, Lane 4 Normal fasted, Lane 5 Standard, Lanes 6-8 8-day diabetic fasted; E Lane 1 443 nt control, Lanes 2-3 Normal fed, Lanes 4-7 Normal fasted, Lane $8250 \mathrm{nt}$ control, Lane $9300 \mathrm{nt}$ control; F Lane 1 $300 \mathrm{nt}$ control, Lane $2250 \mathrm{nt}$ control, Lanes 3-4 Normal fasted, Lane 5 3-day diabetic fasted, Lane 6 8-day diabetic fasted, Lane 7 3-day diabetic fed, Lane 8 3-day diabetic fed, Lane 9 443 nt control; G Lane 1300 nt, Lane 2443 nt, Lane $3250 \mathrm{nt}$, Lane 4 Normal fasted, Lanes 5-6 3-day diabetic fasted, Lanes 7-8 3-day diabetic fed; H Lane 1300 nt control, Lane $2443 \mathrm{nt}$ control, Lane $3250 \mathrm{nt}$ control, Lane 4 Normal fasted, Lanes 5-6 8-day diabetic fasted, Lanes 7-8 8-day diabetic fed

In summary, total synthase specific activity increased progressively with length of diabetes. This occurred in both fed and fasted rats. The modest increase in total synthase specific activity in 3-day diabetic rats compared to controls could be due to a modest increase in protein mass and an increased synthesis rate which was greater than the increased degradation rate. This was associated with an increase in synthase mRNA abundance. However, in neither fed nor fasted 8-day diabetic rats, can the increase in activity be explained by an increase in protein mass. The mass was actually decreased modestly compared to normal rats. The decreased protein in 8-day diabetic fasted rats was associated with a marked decrease in synthase mRNA abundance 
suggesting that the synthesis and turnover rate are likely to have been reduced. In 8-day diabetic fed rats, this was not the case. The same protein mass was associated with an increase in mRNA compared to normal controls. Thus, the synthesis and degradation of synthase protein is regulated differently in fed and fasted diabetic rats. Overall, the data also indicate that the increased synthase enzyme activity in both fed and fasted diabetic animals is due to an increase in synthase catalytic efficiency. The latter is likely to be due to a post-translational modification or the presence of tightly bound effectors.

The increase in synthase activity was limited to the $\mathrm{D}$ form of the enzyme. Thus, the post-translational modification or presence of tightly bound effectors also must be affecting only this form of the enzyme. It generally is considered that the glucose 6-phosphate dependency is related to the total phosphorylation state of the enzyme, thus the increased synthase $\mathrm{D}$ observed could be due to an increase in total amount of phosphate present. However, it also may be due not to a difference in total phosphorylation, but rather to a difference in site specific phosphorylation.

In rats made diabetic with streptozotocin and studied 3 weeks later, synthase activity and synthase mRNA have been reported to be similar to control animals [26]. The reason for the discrepancy between the current data and the previously reported data is not clear. It may be due to the length of time the rats were diabetic as well as a difference in the severity of diabetes in the two studies.

Total phosphorylase specific activity was decreased in liver of 3-and 8-day diabetic rats in the present study. A decrease in total phosphorylase activity has been reported previously in streptozotocin diabetic rats [26, 27]. Also, recently this was reported to be associated with a $45 \%$ decrease in phosphorylase mRNA abundance but no change in transcription rate [26].

In normal fed and $24 \mathrm{~h}$ fasted rats, total synthase specific activity in liver changed little. In addition, the mass of synthase protein, determined by Western blotting, was similar as has been reported previously [28]. However, the mRNA abundance was increased approximately 1.7 -fold in normal fed compared to $24 \mathrm{~h}$ fasted rats. Since the total enzyme protein was unchanged in the presence of increased mRNA, either translation was inhibited or turnover was increased.

In this regard, Wititsuwannakul and Kim [29] reported that the half-life was increased from $4.2 \mathrm{~h}$ in fasted rats to $8.5 \mathrm{~h}$ in fed rats, i.e. just opposite of what one would expect with an increase in mRNA and a subsequent increase in translation rate. Therefore, translation most likely is inhibited.

In 72-h fasted, normal rats Nur et al. [30] reported a $60 \%$ decrease in total synthase specific activity, a
$64 \%$ decrease in synthase protein mass, and no change in mRNA abundance. They speculated that the change in protein mass also may have been due to a change in efficiency of synthase mRNA translation. Shorter periods of starvation were not studied. Thus, their data cannot be compared with those in the present study.

The physiological significance of a change in synthase turnover rate, synthesis rate, and mRNA abundance, without a change in synthase total activity or mass is not apparent. However, a change in synthesis rate could be playing a role in regulation of the enzyme which is not evident from the catalytic kinetics. Liver synthase is a very highly phosphorylated protein containing 14-17 phosphoryl groups/subunits [31]. Six of these turn over with a half-life of about $30 \mathrm{~min}$ and are important in determining the kinetic characteristics of the enzyme [32]. They also are important in the rapid regulation of activity by a phosphorylation-dephosphorylation mechanism in vivo [15]. The remaining phosphoryl groups have been considered to be constitutive. However, it is possible that these phosphorylated amino acids are playing a subtle and as yet poorly understood role in regulation. In order to alter phosphorylation at these sites, turnover of the enzyme itself may be required. An increased turnover as observed in fasted rats would allow more rapid regulation of these sites on the enzyme. For example, they could determine the affinity for different forms of glycogen substrate, affect location in the cell [33], or the substrate suitability for synthase phosphatase [25].

A cknowledgements. Supported by grant \# R01 DK 43018 from the National Institutes of Health, and Merit Review Research Funds from the Department of Veterans Affairs. The authors would like to thank Ping Pei, M.T., Cara Beazley, B.S., and Beverly Hesby, M. T. for excellent technical assistance; Neng Qian Chen, Ph.D. for assistance in raising antibodies in chickens; and Claudia Durand for excellent clerical assistance.

\section{References}

1. Niewoehner CB, Nuttall FQ (1986) Mechanism of stimulation of liver glycogen synthesis by fructose in alloxan diabetic rats. Diabetes 35(6):705-711

2. Gold AH (1970) The effect of diabetes and insulin on liver glycogen synthetase activation. J Biol Chem 245: 903-905

3. Bahnak BR, Gold AH (1982) Effects of alloxan diabetes on the turnover of rat liver glycogen synthase. Comparison with liver phosphorylase. J Biol Chem 257(15):8775-8780

4. Hornbrook KR (1970) Synthesis of liver glycogen in starved alloxan diabetic rats. Diabetes 19: 916-923

5. Akatsuka A, Singh TJ, Huang KP (1983) Comparison of the liver glycogen synthase from normal and streptozotocin-induced diabetic rats. Arch Biochem Biophys 220(2):426-434

6. Steiner DF, Rauda V, Williams RH (1961) Effects of insulin, glucagon, and glucocorticoids upon hepatic glycogen synthesis from uridine diphosphate glucose. J Biol Chem 236: 299-304 
7. Kreutner W, Goldberg ND (1967) Dependence on insulin of the apparent hydrocortisone activation of hepatic glycogen synthetase. Proc Natl Acad Sci USA 58: 1515-1519

8. Miller TB, Vicalvi JJ, Garnache AK (1981) Alteration of hepatic glycogen synthase phosphatase activity by insulin deficiency. Am J Physiol 240:E539-E543

9. Bahnak BR, Gold AH (1982) Isolation and characterization of liver glycogen synthase from diabetic rats. Arch Biochem Biophys 213(2):492-503

10. Nuttall FQ, Gannon MC (1994) Liver glycogen synthase activity, protein mass and mRNA expression in liver from normal fed and fasted and diabetic fed and fasted rats. FASEB/ASBMB meeting, Washington, DC, May 21-25, 1994. Page 11, program addendum. Abst \#2 B21

11. Tan AWH (1979) A simplified method for the preparation of pure UDP $\left[{ }^{14} \mathrm{C}\right]$ glucose. Biochim Biophys Acta 582: 543-547

12. Nuttall FQ, Gannon MC (1989) An improved assay for hepatic glycogen synthase in liver extracts with emphasis on synthase R. Analyt Biochem 178: 311-319

13. Gilboe DP, Larson KL, Nuttall FQ (1972) A radioactive method for the assay of glycogen phosphorylases. Analyt Chem 47: 20-27

14. Zak B, Cohen J (1961) Automatic analysis of tissue culture proteins with stable Folin reagents. Clin Chim Acta 6: 665670

15. Carr RS, Neff JM (1984) Quantitative semi-automated enzymatic assay for tissue glycogen. Comp Biochem Physiol 77B(3):447-449

16. Chomczynski P (1993) A reagent for the single-step simultaneous isolation of RNA, DNA and proteins from cell and tissue samples. BioTechniques 15: 532-537

17. Chomczynski P, Sacchi N (1987) Single step methods for RNA isolation by acid guanidinium thiocyanate-phenolchloroform extraction. Analyt Biochem 162: 156-159

18. Sarkar G, Yoon H-S, Sommer SS (1992) Dideoxy fingerprinting $(\mathrm{ddF})$ : a rapid and efficient screen for the presence of mutations. Genomics 13: 441-443

19. Bai G, Zhang Z, Werner R, Nuttall FQ, Tan AWH, Lee EYC (1990) The primary structure of rat liver glycogen synthase deduced by cDNA cloning. J Biol Chem 265(14):7843-7848

20. Gannon MC (1993) The effect of oral casein on hepatic glycogen metabolism in fasted rats. Metabolism 42(5):649-653

21. Ercan N, Gannon MC, Nuttall FQ (1994) Liver glycogen synthase, phosphorylase and glycogen concentration in rats given a single glucose load orally. A 24 hour study. Arch Biochem Biophys 315(1):35-40

22. Ercan N, Gannon MC, Nuttall FQ (1994) Incorporation of glycogenin into hepatic proteoglycogen after oral glucose administration. J Biol Chem 269(35):22328-22333

23. Gannon MC, Nuttall FQ (1995) Physiological doses of oral casein affect hepatic glycogen metabolism in normal fooddeprived rats. J Nutr 125: 1159-1166

24. Niewoehner C, Nuttall FQ (1995) Glycogen concentration and regulation of synthase activity in rat liver in-vivo. Arch Biochem Biophys 318(2):271-278

25. Tan AWH, Nuttall FQ (1976) Regulation of synthase phosphatase and phosphorylase phosphatase in rat liver. Biochim Biophys Acta 445: 118-130

26. Rao PV, Pugazhenthi S, Khandelwal RL (1995) The effects of streptozotocin-induced diabetes and insulin supplementation on expression of the glycogen phosphorylase gene in rat liver. J Biol Chem 270(42):24955-24960

27. Khandelwal RL, Zinman SM, Zebrowski EJ (1977) The effect of streptozotocin-induced diabetes and of insulin supplementation on glycogen metabolism in rat liver. Biochem J 168: 541-548

28. Giffin BF, Drake RI, Morris RE, Cardell RR (1993) Hepatic lobular patterns of phosphoenolpyruvate carboxykinase, glycogen synthase, and glycogen phosphorylase in fasted and fed rats. J Histochem Cytochem 41(12):18491862

29. Wititsuwannakul D, Kim K-H (1979) Immunological studies of liver glycogen synthase. Relative significance of covalent modification and changes in the rate of synthesis and degradation. J Biol Chem 254(9):3562-3569

30. Nur T, Sela I, Webster NJG, Madar Z (1995) Starvation and refeeding regulate glycogen synthase gene expression in rat liver at the post-transcriptional level. J Nutr 125: 2457-2462

31. Tan AWH, Nuttall FQ (1983) Endogenous phosphates on liver glycogen synthase D and synthase I. Studies on the number and location. J Biol Chem 258: 9624-9630

32. Tan AWH, Nuttall FQ (1985) In-vivo phosphorylation of liver glycogen synthase. Isolation of the ${ }^{32} \mathrm{P}$-labelled enzyme and studies on the nature of the bound $\left[{ }^{32} \mathrm{P}\right]$ phosphates. J Biol Chem 260(8):4751-4757

33. Fernandez-Novell JM, Arino J, Vilaro S, Guinovart JJ (1992) Glucose induces the translocation and the aggregation of glycogen synthase in rat hepatocytes. Biochem $\mathbf{J}$ 281: 433-448 